\title{
Hyperglycaemia compensates for the defects in insulin-mediated glucose metabolism and in the activation of glycogen synthase in the skeletal muscle of patients with Type 2 (non-insulin-dependent) diabetes mellitus
}

\author{
A. Vaag ${ }^{1,2}$, P.Damsbo ${ }^{2}$, O.Hother-Nielsen ${ }^{1,2}$ and H. Beck-Nielsen ${ }^{1,2}$ \\ ${ }^{1}$ Department of Endocrinology and Internal Medicine M, Odense University Hospital, Odense, and \\ ${ }^{2}$ Hvidöre Hospital, Klampenborg, Denmark
}

Summary. Insulin resistance and a defective insulin activation of the enzyme glycogen synthase in skeletal muscle during euglycaemia may have important pathophysiological implications in Type 2 (non-insulin-dependent) diabetes mellitus. Hyperglycaemia may serve to compensate for these defects in Type 2 diabetes by increasing glucose disposal through a mass action effect. In the present study, rates of whole-body glucose oxidation and glucose storage were measured during fasting hyperglycaemia and isoglycaemic insulin infusion $\left(40 \mathrm{mU} \cdot \mathrm{m}^{-2} \cdot \mathrm{min}^{-1}, 3 \mathrm{~h}\right)$ in 12 patients with Type 2 diabetes. Eleven control subjects were studied during euglycaemia. Biopsies were taken from the vastus lateralis muscle. Fasting and insulin-stimulated glucose oxidation, glucose storage and muscle glycogen synthase activation were all fully compensated (normalized) during hyperglycaemia in the diabetic patients. The insulin-stimulated increase in muscle glycogen content was the same in the diabetic patients and in the control subjects. Besides hyperglycaemia, the diabetic patients had elevated muscle free glucose and glucose 6-phosphate concentrations. A positive correlation was demonstrated between intracellular free glucose concentration and muscle glycogen synthase fractional velocity insulin activation $(0.1 \mathrm{mmol} / \mathrm{l}$ glucose 6 -phosphate: $r=0.65, p<0.02$ and $0.0 \mathrm{mmol} / 1$ glucose 6-phosphate: $r=$ $0.91, p<0.0001)$. In conclusion, this study indicates an important role for hyperglycaemia and elevated muscle free glucose and glucose 6-phosphate concentrations in compensating (normalizing) intracellular glucose metabolism and skeletal muscle glycogen synthase activation in Type 2 diabetes.

Key words: Glycogen synthase, skeletal muscle, Type 2 (noninsulin-dependent) diabetes mellitus, hyperglycaemia, insulin resistance.
Patients with Type 2 (non-insulin-dependent) diabetes mellitus are characterized by insulin resistance when studied by means of the euglycaemia hyperinsulinaemic clamp technique [1-4]. The insulin resistance occurs in both the oxidative and non-oxidative pathways, although the predominant defect is on non-oxidative glucose metabolism [3-7]. The main site of the insulin resistance is considered to be in skeletal muscle $[3,8]$, and insulinstimulated non-oxidative glucose metabolism is considered primarily to represent muscle glycogen synthesis. The rate limiting key enzyme in this pathway is glycogen synthase $[9,10]$. Glycogen synthase is stimulated covalently (dephosphorylated) by insulin $[10,11]$, and a close correlation between in vivo insulin-stimulated muscle glycogen synthase activity and whole-body non-oxidative glucose disposal has been demonstrated during euglycaemia in subjects with and without Type 2 diabetes $[4$, $10,12]$. In addition, a defective activation of glycogen synthase in skeletal muscle during a euglycaemic insulin infusion is a consistent finding in Type 2 diabetic patients $[4,8,13]$.

Hyperglycaemia increases glucose uptake in peripheral tissues by a mass action effect, and it has been previously demonstrated that when glucose clamp studies are performed at the patients' ambient fasting glucose levels (isoglycaemic hyperinsulinaemic clamp procedure), Type 2 diabetic patients exhibit overall glucose disposal rates that are similar to those observed in normal subjects studied during euglycaemia at similar insulin concentrations [14]. This suggests that the ambient level of fasting hyperglycaemia may compensate for the insulin resistance in Type 2 diabetes.

The aim of the present study was to elucidate the extent of, and the mechanisms behind, a potentially compensated (or normalized) intracellular muscle glucose metabolism and glycogen synthase activation in patients with Type 2 diabetes during fasting hyperglycaemia and isoglycaemic insulin infusion. 
Table 1. Clinical characteristics of the Type 2 (non-insulin-dependent) diabetic patients and control subjects

\begin{tabular}{lcc}
\hline & $\begin{array}{l}\text { Type } 2 \\
\text { diabetic } \\
\text { patients }\end{array}$ & $\begin{array}{c}\text { Control } \\
\text { subjects }\end{array}$ \\
\hline Females/males & $2 / 10$ & $2 / 9$ \\
Age (years) & $56 \pm 3$ & $56 \pm 4$ \\
Body mass index $\left(\mathrm{kg} / \mathrm{m}^{2}\right)$ & $29.4 \pm 1.0^{\mathrm{b}}$ & $24.8 \pm 1.1$ \\
Body surface area $\left(\mathrm{m}^{2}\right)$ & $2.03 \pm 0.04$ & $1.88 \pm 0.05$ \\
Fat free mass $(\mathrm{kg})$ & $59.5 \pm 3.0$ & $56.1 \pm 3.0$ \\
Fasting plasma glucose $(\mathrm{mmol} / \mathrm{l})$ & $10.7 \pm 1.1^{\mathrm{b}}$ & $5.5 \pm 0.1$ \\
Fasting plasma insulin $(\mathrm{nmol} / \mathrm{l})$ & $0.11 \pm 0.01^{\mathrm{b}}$ & $0.06 \pm 0.01$ \\
Fasting plasma C-peptide $(\mathrm{nmol} / \mathrm{l})$ & $0.94 \pm 0.11^{\mathrm{a}}$ & $0.64 \pm 0.11$ \\
Duration of diabetes (years) & $7 \pm 2$ & - \\
Glycated haemoglobin $(\%)$ & $8.5 \pm 0.7^{\mathrm{b}}$ & $5.1 \pm 0.2$ \\
\hline
\end{tabular}

Mean \pm SEM. a $p<0.02$ vs control subjects, ${ }^{b} p<0.01$ vs control subjects

\section{Subjects and methods}

\section{Subjects}

Twelve patients with Type 2 diabetes were compared with a group of age- and sex-matched normal subjects (Table 1). The control subjects were non-obese with normal oral glucose tolerance on testing. None of the control subjects had any familial history of diabetes. The diabetic patients had significantly higher fasting plasma glucose, insulin and C-peptide concentrations according to the nature of their disease. Furthermore, the diabetic patients were more obese than the control subjects. None of the diabetic patients were treated with insulin, and none of the diabetic or control subjects were exercising regularly. Seven patients were being treated with diet alone and five patients were treated with diet and oral hypoglycaemic drugs (sulfonylurea or metformin). Oral hypoglycaemic drugs were withdrawn at least 1 week prior to the studies. The patients with Type 2 diabetes were on a diet consisting of approximately $55 \%$ carbohydrate, $15 \%$ protein and $30 \%$ fat. None of the study subjects had clinical evidence of cardiac, hepatic or renal disease or endocrine disorders other than diabetes. Furthermore, the diabetic patients had no evidence of diabetic neuropathy, nephropathy or proliferative retinopathy. Informed consent was obtained and the study was approved by the regional ethical committee. The procedure was performed according to the principles of the Helsinki Declaration.

\section{In vivo methods}

Isoglycaemic insulin clamp. All studies were started at 07.30 hours after a 10-h overnight fast. A polyethylene catheter was inserted into an antecubital vein for infusion of test substances. Another polyethylene catheter was inserted into a contralateral wrist vein for blood sampling. This hand was placed and maintained in a heated plexiglas box to obtain arterialized venous blood [15]. After a 120min basal equilibration period for basal measurements (Fig. 1), insulin (Actrapid, Novo-Nordisk, Bagsvaerd, Denmark) was infused for $180 \mathrm{~min}$ at a constant rate of $40 \mathrm{mU} \cdot \mathrm{m}^{-2} \cdot \mathrm{min}^{-1}$ in both Type 2 diabetic patients and control subjects. The plasma glucose concentration was maintained using a variable glucose infusion $(1 \mathrm{~mol} / \mathrm{l})$ (isoglycaemic clamp procedure). Thus, the Type 2 diabetic patients were studied at their ambient levels of fasting hyperglycaemia, whereas the control subjects were studied at euglycaemic levels. The plasma glucose concentration was monitored in arterialized blood every 5-10 min using an automated glucose oxidase method (Glucose Analyser 2, Beckman Instruments, Fullerton, Calif., USA).
Steady-state periods were defined as the last $30 \mathrm{~min}$ during basal measurements $(-30-0 \mathrm{~min})$ and the last $30 \mathrm{~min}$ of insulin-stimulated measurements (150-180 min). Urinary glucose excretion was measured during each clamp study in order to correct for this when calculating the total peripheral glucose utilization

Tritiated glucose. The glucose clamp studies were combined with a primed continous infusion of $3{ }^{3} \mathrm{H}$-glucose (New England Nuclear, Boston, Mass., USA) (Fig. 1). In order to ensure isotope equilibrium, the continuous infusion of $3{ }^{3} \mathrm{H}$-glucose $(0.22 \mu \mathrm{Ci} / \mathrm{min})$ was begun $90-120 \mathrm{~min}$ before measurements of glucose turnover were performed, and the priming dose of $3-{ }^{3} \mathrm{H}$-glucose was increased in proportion to fasting hyperglycaemia in the Type 2 diabetic patients according to the formula: priming dose $=22 \mu \mathrm{Ci} \times$ plasma glucose concentration ( $\mathrm{mmol} / \mathrm{l}) / 5(\mathrm{mmol} / \mathrm{l})$ [16]. During steady-state periods, blood samples were drawn in fluoride-treated tubes at $10-\mathrm{min}$ intervals for determination of plasma glucose and plasma $3-{ }^{3} \mathrm{H}$-glucose activity. During the remainder of the study period, plasma glucose and $3{ }^{3} \mathrm{H}$-glucose activity was measured every $30 \mathrm{~min}$.

Indirect calorimetry. Indirect calorimetry was performed using a computerized flowthrough canopy gas analyser system (Deltatrac, Datex, Helsinki, Finland). Briefly, air is suctioned at a rate of 40 litres per min through a canopy placed over the head of the subject. Samples of inspired and expired air are analysed for oxygen concentration using a paramagnetic differential oxygen sensor and for carbon dioxide using an infra-red carbon dioxide sensor. Signals from the gas analysers are processed by the computer and oxygen consumption and carbon dioxide production are calculated and recorded once per min. After an equilibration period of $10 \mathrm{~min}$, the average gas exchange rates recorded over the two 30-min steadystate periods (Fig. 1) were used to calculate rates of glucose oxidation, lipid oxidation and energy expenditure as previously described $[17,18]$. The protein oxidation rate was estimated from urinary urea nitrogen excretion ( $1 \mathrm{~g}$ nitrogen $=6.25 \mathrm{~g}$ protein) and corrected for changes in pool size [19].

Muscle biopsy. Muscle biopsies were performed using a modified Bergström needle (including suction) under local anaesthesia. The

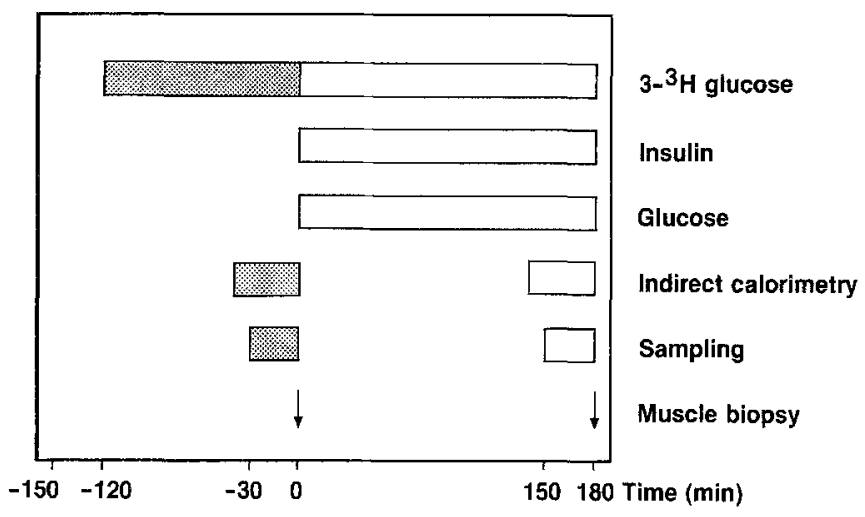

Fig. 1. Experimental study design. Plasma glucose was clamped at the fasting glucose concentration during insulin infusion in both patients with Type 2 (non-insulin-dependent) diabetes mellitus and normal control subjects (isoglycaemic clamp procedure). Thus, hyperglycaemia was maintained in the diabetic patients during the insulin infusion, whereas euglycaemia was maintained in the control subjects. Each isoglycaemic clamp study was preceded by a 120 -min period for basal measurements (solid bars). Insulin was infused for $180 \mathrm{~min}$ at a rate of $40 \mathrm{mU} \cdot \mathrm{m}^{-2} \cdot \mathrm{min}^{-1}$. Steady-state measurements of glucose turnover were made, and indirect calorimetry was carried out during the last $30 \mathrm{~min}$ of basal and clamp periods. During this time, plasma was analysed for glucose, insulin, C-peptide, non-esterified fatty acids (NEFA) and lactate. Muscle biopsies were taken from the vastus lateralis muscle in the basal state and after $180 \mathrm{~min}$ insulin infusion 
biopsies were rapidly (within 10-15 s) frozen and stored in liquid nitrogen for later analysis. Before the biochemical analysis the muscle samples were freeze-dried and dissected free of visible connective tissue, fat and blood.

Calculations. During the steady-state periods, glucose turnover rates (hepatic glucose output (HGO) and total peripheral glucose disposal) were calculated at 10-min intervals using Steele's non-steadystate equations [20]. Non-steady-state equations were used during basal measurements because of spontaneously declining plasma glucose concentrations in the Type 2 diabetic patients. In these calculations, the distribution volume of glucose was taken as $200 \mathrm{ml} / \mathrm{kg}$ body weight and the pool fraction as 0.65 [21]. During the insulin infusion periods negative rates of HGO were calculated in all subjects. Such underestimation of glucose turnover by the tracer method is largely accounted for by a model error emerging at high rates of glucose metabolism [22]. We took the negative numbers to indicate a nil HGO. Thus, because HGO was negative during the insulin infusion in all of the subjects studied, the infusion rate of exogenous glucose was equal to total peripheral glucose disposal. Total peripheral glucose disposal was corrected for urinary glucose excretion. Non-oxidative glucose metabolism (glucose storage) was calculated as the difference between total body glucose utilization and glucose oxidation, as determined by indirect calorimetry.

Glucose and lipid metabolism data were expressed as $\mathrm{mg}$ per $\mathrm{kg}$ fat free mass (FFM) per min. Total body fat and thus FFM was measured using the bioimpedance method [23].

\section{In vitro methods}

Glycogen and metabolite concentrations in muscle biopsies. Glycogen was measured as glucose residues after hydrolysis of the muscle samples, in $1 \mathrm{~mol} / \mathrm{h} \mathrm{HCL}$ at $100^{\circ} \mathrm{C}$ for $2 \mathrm{~h}$ [24]. Glucose, glucose 6-phosphate (G6P) and lactate were measured fluorometrically on neutralized perchloric acid extracts [24]. Intracellular concentrations of free glucose, G6P and lactate were calculated as millimoles per litre of intracellular water, assuming an extracellular water content in the biopsies of $0.31 / \mathrm{kg}$ dry weight and an intracellular water content of $2.81 / \mathrm{kg}$ dry weight $[25,26]$. Intracellular concentrations of free glucose and lactate were corrected for extracellular concentrations using the above assumptions of intracellular and extracellular water content in the biopsies.

Glycogen synthase activity. Extraction of muscle samples and assays for glycogen synthase were performed as we previously described [4, 10] by a modification of the method of Thomas et al. [27]. Glycogen synthase activity was assayed without adding its allosteric modulator G6P, in the presence of a near physiological concentration of G6P $(0.1 \mathrm{mmol} / \mathrm{l})$ and in the presence of a high $\mathrm{G} 6 \mathrm{P}$ concentration $(10 \mathrm{mmol} / 1)$. This concentration was used to determine maximal enzyme activity. The total concentration of uridine diphosphate glucose $\left({ }^{14} \mathrm{C}-\mathrm{UDPG}+\right.$ cold UDPG) in the reaction mixture was $0.31 \mathrm{mmol} / \mathrm{l}$. Glycogen synthase activity was expressed as nanomoles of UDPG incorporated into glycogen per min per milligram extract protein. Fractional velocities (FV) of the enzyme were calculated as the ratio between glycogen synthase activities assayed at $0 \mathrm{mmol} / \mathrm{l}$ G6P and $10 \mathrm{mmol} / 1 \mathrm{G} 6 \mathrm{P}$ (FV 0.0) and at $0.1 \mathrm{mmol} / 1 \mathrm{G} 6 \mathrm{P}$ and $10 \mathrm{mmol} / 1 \mathrm{G} 6 \mathrm{P}$ (FV 0.1). The fractional velocities of glycogen synthase in muscle biopsies have previously been demonstrated to correlate with in vivo non-oxidative glucose metabolism during a euglycaemic insulin infusion $[4,10,12]$, and fractional velocities are therefore thought to merely reflect the in vivo covalent activation of the enzyme. Protein content of the extracts was determined by the method of Lowry et al. [28].

Analytical determinations. Glucose in plasma and urine was determined by a hexokinase method [29]. Tritiated glucose activity was measured as described by Hother-Nielsen and Beck-Nielsen [16]. Plasma insulin [30] and C-peptide [31] concentrations were measured with radioimmunological methods. Non-esterified fatty acids (NEFA) in plasma were determined by the method of Itaya et al. [32] and lactate by the method of Passonneau [33]. Plasma concentrations of glucose, insulin, C-peptide, NEFA and lactate were measured at 10 -min intervals during both steady-state periods. $\mathrm{HbA}_{1 \mathrm{c}}$ was measured by isoelectric focussing [34] (normal range 4.1-6.1\%).

\section{Statistical analysis}

Non-parametric statistical methods (Wilcoxon test for paired data, Mann-Whitney test for unpaired data, and Spearmans rho $(r)$ for correlation analysis) were employed in analysis of data. $p$ values less than 0.05 were considered significant. Data in text and figures are presented as the mean \pm SEM.

\section{Results}

Plasma glucose, insulin, C-peptide, NEFA and lactate concentrations during clamp studies are given in Table 2. Plasma glucose concentrations were significantly higher in the Type 2 diabetic patients during the basal postprandial state and during insulin infusion. Mean coefficients of variation of plasma glucose concentrations during insulin-stimulated steady-state periods were small and similar in diabetic patients and control subjects $(3 \pm 1$ vs $5 \pm 1 \%$, NS). Plasma insulin and C-peptide concentrations were significantly higher in the diabetic patients in the basal state. The higher insulin and C-peptide concentrations during insulin infusion did not reach statistical significance. Increments in plasma insulin concentrations during insulin infusions were identical in diabetic patients and control subjects $(0.41 \mathrm{vs} 0.37 \mathrm{nmol} / 1$, NS).

Plasma lactate concentrations were elevated in the diabetic patients in both the basal state and during insulin infusion, whereas plasma NEFA concentrations were normal.

Isotopic steady-state (constant plasma concentration of $3-{ }^{3} \mathrm{H}$-glucose) was obtained during the pre-defined basal steady-state period in both diabetic patients and

Table 2. Plasma glucose (PG), insulin (PI), C-peptide (PC-pep), non-esterified fatty acids (NEFA) and lactate concentrations during clamp studies. BSS: Basal steady-state. ISS: Insulin-stimulated steady-state $\left(3 \mathrm{~h}, 40 \mathrm{mU} \cdot^{-2} \cdot \mathrm{min}^{-1}\right)$

\begin{tabular}{llc}
\hline & $\begin{array}{l}\text { Type } 2 \\
\text { diabetic } \\
\text { patients } \\
(n=12)\end{array}$ & $\begin{array}{l}\text { Control } \\
\text { subjects } \\
(n=11)\end{array}$ \\
\hline BSS-PG $(\mathrm{mmol} / \mathrm{l})$ & $10.5 \pm 1.1^{\mathrm{b}}$ & $5.5 \pm 0.1$ \\
ISS-PG $(\mathrm{mmol} / \mathrm{l})$ & $10.3 \pm 1.1^{\mathrm{b}}$ & $5.5 \pm 0.5$ \\
BSS-PI $(\mathrm{nmol} / \mathrm{l})$ & $0.11 \pm 0.01^{\mathrm{b}}$ & $0.06 \pm 0.01$ \\
ISS-PI $(\mathrm{nmol} / \mathrm{l})$ & $0.52 \pm 0.04$ & $0.43 \pm 0.04$ \\
BSS-C-pep. $(\mathrm{nmol} / \mathrm{l})$ & $0.94 \pm 0.11^{\mathrm{a}}$ & $0.64 \pm 0.11$ \\
ISS-C-pep. $(\mathrm{nmol} / \mathrm{l})$ & $0.75 \pm 0.09$ & $0.56 \pm 0.10$ \\
BSS-NEFA $(\mathrm{mmol} / \mathrm{l})$ & $0.64 \pm 0.06$ & $0.70 \pm 0.07$ \\
ISS-NEFA $(\mathrm{mmol} / \mathrm{l})$ & $0.09 \pm 0.02$ & $0.05 \pm 0.01$ \\
BSS-Lactate $(\mathrm{mmol} / \mathrm{l})$ & $0.87 \pm 0.06^{\mathrm{b}}$ & $0.49 \pm 0.05$ \\
ISS-Lactate $(\mathrm{mmol} / \mathrm{l})$ & $0.96 \pm 0.10^{\mathrm{a}}$ & $0.77 \pm 0.07$ \\
\hline
\end{tabular}

Mean \pm SEM. ${ }^{a} p<0.02$ vs control subjects, ${ }^{b} p<0.01$ vs control subjects 
control subjects. Insulin-stimulated rates of total peripheral glucose utilization, glucose oxidation and non-oxidative glucose metabolism were similar in the Type 2 diabetic patients during hyperglycaemia and in the control subjects during euglycaemia (Table 3 ).

In the basal state, the total glucose utilization rate was slightly elevated in the diabetic patients (Table 3 ). This was due to elevated rates of both glucose oxidation and glucose storage, although neither of these differences reached statistical significance when tested separately. Basal HGO was slightly elevated in the diabetic patients, when expressed both as $\mathrm{mg}$ glucose $\cdot \mathrm{m}^{-2} \cdot \min ^{-1}(86 \pm 2 \mathrm{vs}$ $78 \pm 3, p<0.05)$, or as $\mathrm{mg}$ glucose $\cdot(\mathrm{kg} \mathrm{FFM})^{-1} \cdot \mathrm{min}^{-1}(3.1$ \pm 0.1 vs $2.7 \pm 0.2, p<0.05)$. In the diabetic patients, the basal glucose utilization rate exceeded the basal HGO $\left(3.3 \pm 0.2\right.$ vs $\left.3.1 \pm 0.1 \mathrm{mg} \cdot\left(\mathrm{kg} \mathrm{FFM}{ }^{-1}\right) \cdot \mathrm{min}^{-1}, p<0.05\right)$. Thus, a spontaneously falling plasma glucose concentration was observed during the 2 - $h$ basal state in the diabetic patients.

No difference in lipid oxidation (Table 3) was found in the basal state between diabetic patients $\left(1.13 \pm 0.08 \mathrm{mg} \cdot(\mathrm{kg} \mathrm{FFM})^{-1} \cdot \mathrm{min}^{-1}\right)$ and control subjects $\left(1.45 \mathrm{mg} \cdot(\mathrm{kg} \mathrm{FFM})^{-1} \cdot \mathrm{min}^{-1}\right)$. Furthermore, the lipid oxidation was equally suppressed during insulin infusion in the diabetic patients $\left(0.50 \pm 0.02 \mathrm{mg} \cdot(\mathrm{kg} \mathrm{FFM})^{-1} \cdot \mathrm{min}^{-1}\right)$ and in the control subjects $\left(0.71 \pm 0.13 \mathrm{mg} \cdot(\mathrm{kg} \mathrm{FFM})^{-1}\right.$. $\min ^{-1}$ ).

Muscle glycogen synthase activities, expressed as fractional velocities, were stimulated by insulin in all the Type 2 diabetic patients and control subjects (Table 4). No difference in insulin sensitivity of muscle glycogen synthase activity was found between patients with Type 2 diabetes or the control subjects.

Muscle glycogen content increased significantly in the diabetic patients during the isoglycaemic insulin infusion (Table 5). The insulin-stimulated increase in muscle glycogen content in the normal subjects was similar to the diabetic (i.e. $28 \mathrm{mmol} / \mathrm{kg}$ dry weight), although this increase was not statistically significant.

A significantly higher muscle free glucose concentration was found in the patients with Type 2 diabetes in the basal state and during insulin infusion (Table 5). No correlation was found between the plasma glucose concentration and the intracellular concentration of free glucose in the diabetic patients $(r=0.08, \mathrm{NS})$, indicating that the free glucose concentration in the diabetic patients was not overestimated. The patients with Type 2 diabetes had a higher muscle G6P concentration in the basal state and during insulin infusion. The difference in G6P concentrations, however, was only statistically significant during insulin infusion. The higher muscle lactate concentration in the diabetic patients was not statistically significant $(p<0.07$ during insulin infusion). Muscle free glucose, G6P and lactate concentrations remained unchanged during insulin infusion in both diabetic patients and control subjects.

In the patients with Type 2 diabetes, the insulin-stimulated increase in fractional glycogen synthase activity at $0.1 \mathrm{mmol} / \mathrm{G} 6 \mathrm{P}$ (FV 0.1) correlated significantly with the insulin-stimulated increase in non-oxidative glucose disposal $(r=0.65, p<0.03$, Fig. 2). No significant correlation was found between insulin-stimulated increase in frac-
Table 3. Rates of total peripheral glucose utilization, glucose oxidation and glucose storage (non-oxidative glucose metabolism) during fasting hyperglycaemia (basal period) and isoglycaemic insulin infu$\operatorname{sion}\left(3 \mathrm{~h}, 40 \mathrm{mU} \cdot \mathrm{m}^{-2} \cdot \mathrm{min}^{-1}\right)$ in 12 Type 2 (non-insulin-dependent) diabetic patients. Eleven age- and sex-matched normal subjects were studied during fasting euglycaemia and euglycaemic insulin infusion $\left(3 \mathrm{~h}, 40 \mathrm{mU} \cdot \mathrm{m}^{-2} \cdot \mathrm{min}^{-1}\right)$

\begin{tabular}{llllll}
\hline & \multicolumn{2}{l}{$\begin{array}{l}\text { Type 2 diabetic } \\
\text { patients }\end{array}$} & & \multicolumn{2}{l}{ Control subjects } \\
\cline { 2 - 3 } \cline { 5 - 6 } \cline { 5 - 6 } & Basal & Insulin & & Basal & Insulin \\
\hline $\begin{array}{l}\text { Total glucose utiliza- } \\
\text { tion }\end{array}$ & $3.3 \pm 0.2^{\mathrm{a}}$ & $8.4 \pm 1.2$ & & $2.5 \pm 0.1$ & $9.2 \pm 0.9$ \\
Glucose oxidation & $1.8 \pm 0.2$ & $3.4 \pm 0.3$ & & $1.3 \pm 0.1$ & $3.2 \pm 0.2$ \\
Glucose storage & $1.5 \pm 0.2$ & $5.0 \pm 1.1$ & & $1.2 \pm 0.2$ & $6.0 \pm 0.7$ \\
\hline
\end{tabular}

Data are $\mathrm{mg}$ glucose $\cdot(\mathrm{kg} \text { fat free mass })^{-1} \cdot \min ^{-1}, \overline{\text { mean } \pm \mathrm{SEM}}$, ${ }^{a} p<0.01$ vs control subjects

Table 4. Activities of skeletal muscle glycogen synthase in 12 patients with Type 2 (non-insulin-dependent) diabetes mellitus and in 11 control subjects. Biopsies were taken from the vastus lateralis muscle in the basal postabsorptive state and after $3 \mathrm{~h}$ insulin infusion $\left.40 \mathrm{mU} \cdot{ }^{-2} \cdot \mathrm{min}^{-1}\right)$. Glycogen synthase activities are given as nmol UDP-glucose incorporated into glycogen per $\mathrm{mg}$ extract protein per min. Glycogen synthase activities were measured in the absence of its allosteric modulator glucose 6-phosphate ( $0.0 \mathrm{mmol} / \mathrm{l} \mathrm{G6P})$, in the presence of a physiological $\mathrm{G} 6 \mathrm{P}$ concentration $(0.1 \mathrm{mmol} / 1)$, and in the presence of a maximal stimulatory $\mathrm{G} 6 \mathrm{P}$ concentration $(10 \mathrm{mmol} / \mathrm{l})$. Fractional velocities (FV) are given in $\%$

\begin{tabular}{lccccc}
\hline & \multicolumn{2}{l}{$\begin{array}{l}\text { Type 2 diabetic } \\
\text { patients }\end{array}$} & & \multicolumn{2}{l}{ Control subjects } \\
\cline { 2 - 3 } \cline { 5 - 6 } \cline { 5 - 6 } & Basal & Insulin & & Basal & Insulin \\
\hline 0.0 mmol G6P & $0.09 \pm 0.02$ & $0.28 \pm 0.08^{\mathrm{a}}$ & & $0.15 \pm 0.04$ & $0.24 \pm 0.03^{\mathrm{a}}$ \\
$0.1 \mathrm{mmol} \mathrm{G6P}$ & $0.60 \pm 0.08$ & $1.14 \pm 0.25^{\mathrm{a}}$ & & $0.94 \pm 0.23$ & $1.31 \pm 0.15^{\mathrm{a}}$ \\
$10 \mathrm{mmol} \mathrm{G6P}$ & $2.53 \pm 0.30$ & $2.63 \pm 0.54$ & & $3.13 \pm 0.58$ & $2.78 \pm 0.38$ \\
FV 0.0 & $5 \pm 1$ & $11 \pm 2^{\mathrm{a}}$ & & $5 \pm 1$ & $9 \pm 1^{\mathrm{a}}$ \\
FV 0.1 & $25 \pm 3$ & $45 \pm 5^{\mathrm{a}}$ & & $29 \pm 2$ & $49 \pm 2^{\mathrm{a}}$ \\
\hline
\end{tabular}

Mean \pm SEM. a $p<0.01$ vs basal measurements

Table 5. Intracellular concentrations of free glucose, glucose 6phosphate (G6P), glycogen and lactate in the skeletal muscle in 12 patients with Type 2 (non-insulin-dependent) diabetes mellitus and in 11 normal control subjects. Concentrations of free glucose, G6P and lactate are given as mmol/ intracellular water, assuming an extracellular water content in muscle biopsies of $0.3 \mathrm{l} / \mathrm{kg}$ dry weight and an intracellular water content of $2.81 / \mathrm{kg}$ dry weight. Muscle glycogen content is given as $\mathrm{mmol}$ glucose residues $/ \mathrm{kg}$ dry weight

\begin{tabular}{llllcc}
\hline & \multicolumn{2}{l}{$\begin{array}{l}\text { Type 2 diabetic } \\
\text { patients }\end{array}$} & & \multicolumn{2}{l}{ Control subjects } \\
\cline { 2 - 3 } \cline { 5 - 6 } \cline { 5 - 6 } & Basal & Insulin & & Basal & Insulin \\
\hline Glucose & $0.43 \pm 0.12^{\mathrm{a}}$ & $0.42 \pm 0.13^{\mathrm{b}}$ & & $-0.01 \pm 0.05$ & $-0.05 \pm 0.03$ \\
G6P & $0.14 \pm 0.05$ & $0.12 \pm 0.03^{\mathrm{a}}$ & & $0.06 \pm 0.03$ & $0.04 \pm 0.01$ \\
Glycogen & $372 \pm 17$ & $401 \pm 18^{\mathrm{c}}$ & & $409 \pm 25$ & $437 \pm 17$ \\
Lactate & $2.87 \pm 0.41$ & $3.54 \pm 0.52$ & & $2.27 \pm 0.59$ & $2.66 \pm 0.59$ \\
\hline
\end{tabular}

Mean \pm SEM. ${ }^{a} p<0.05$ vs control subjects, ${ }^{b} p<0.02$ vs control subjects, ${ }^{c} p<0.01$ vs basal measurements

tional velocities at $0.0 \mathrm{mmol} / \mathrm{l} \mathrm{G} 6 \mathrm{P}(\mathrm{FV} 0.0)$ and the increase in non-oxidative glucose disposal in the diabetic patients $(r=0.14, \mathrm{NS})$. In the normal subjects, however, a 

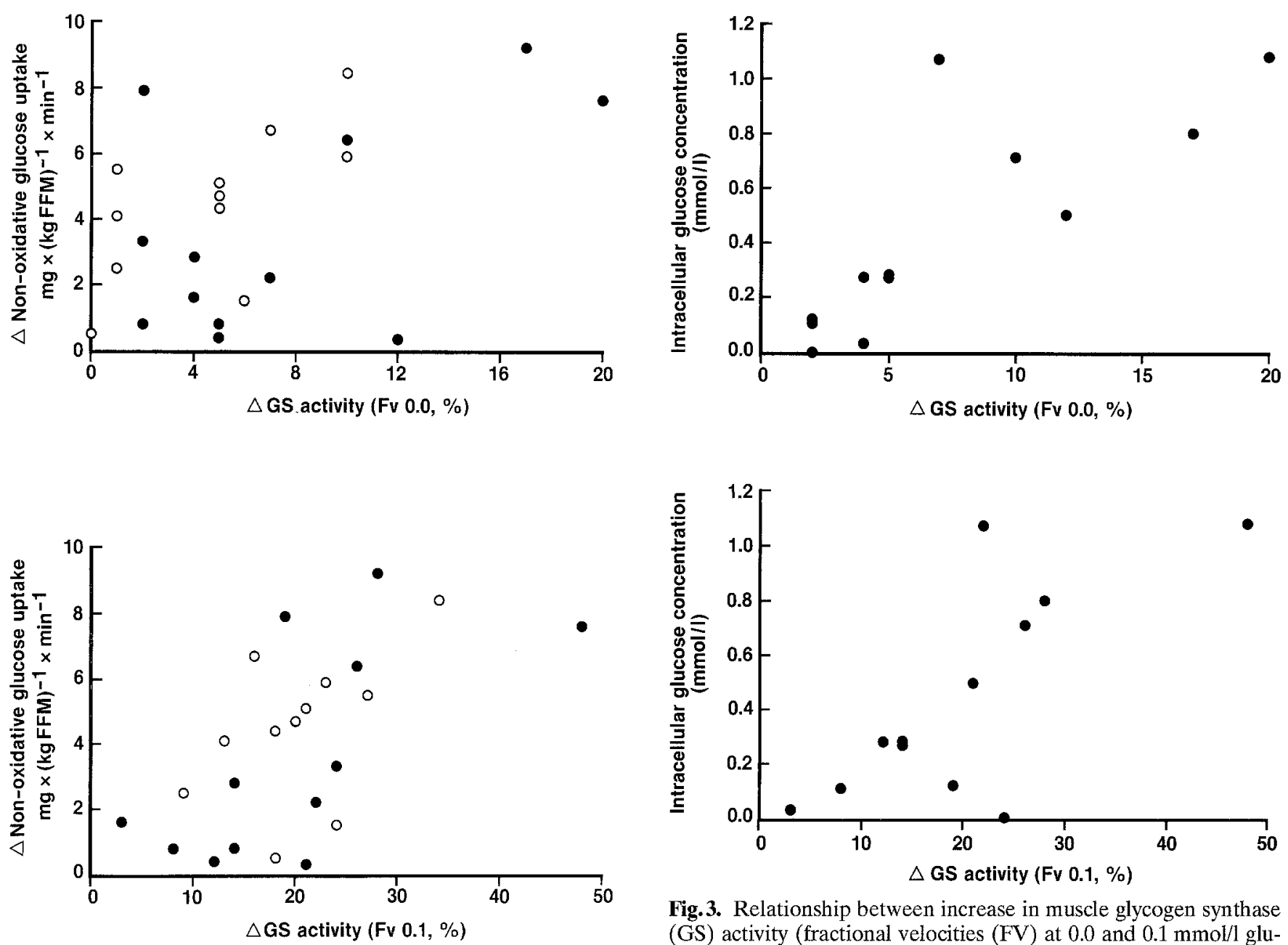

Fig. 2. Relationship between increase in muscle glycogen synthase (GS) activity (fractional velocities (FV) at 0.0 and $0.1 \mathrm{mmol} / \mathrm{l}$ glucose 6-phosphate) and increase in whole-body non-oxidative glucose metabolism during insulin infusion $\left(3 \mathrm{~h}, 40 \mathrm{mU}{ }^{-2} \cdot \mathrm{min}^{-1}\right)$ in 12 patients with Type 2 (non-insulin-dependent) diabetes mellitus $(\bullet ; F V ~ 0.0: r=0.14, \mathrm{NS} ; \mathrm{FV} 0.1: r=0.65, p<0.03$ ) and in 11 normal control subjects (O;FV 0.0: $r=0.69, p<0.02$; FV $0.1: r=0.44, \mathrm{NS})$. $\mathrm{FFM}=$ fat free mass

significant correlation was found between the increase in FV 0.0 and the increase in non-oxidative glucose disposal during insulin infusion $(r=0.69, p<0.02)$, while the correlation between increase in FV 0.1 and increase in non-oxidative glucose disposal was not statistically significant $(r=0.44, p=0.19)$. When correlation analyses were made for the two groups together $(n=23)$, the increase in FV 0.1 correlated with the increase in non-oxidative glucose metabolism $(r=0.58, p<0.005)$, while the correlation between increase in FV 0.0 and increase in nonoxidative glucose disposal did not reach statistical significance $(r=0.35, p=0.1)$.

The intracellular concentration of free glucose (mean of basal + insulin-stimulated) was significantly correlated with the insulin-stimulated increase in fractional glycogen synthase activity (FV 0.1: $r=0.65, p<0.02$ and FV 0.0 : $r=0.91, p<0.001$, Fig. 3 ) in the patients with Type 2 diabetes. A weaker and non-significant correlation was found between the plasma glucose concentration and the

Fig. 3. Relationship between increase in muscle glycogen synthase (GS) activity (fractional velocities (FV) at 0.0 and $0.1 \mathrm{mmol} / \mathrm{l}$ glucose 6-phosphate) during insulin infusion $\left(3 \mathrm{~h}, 40 \mathrm{mU} \cdot{ }^{-2} \cdot \mathrm{min}^{-1}\right)$ and intracellular concentration of free glucose in skeletal muscle in 12 patients with Type 2 (non-insulin-dependent) diabetes mellitus. FV 0.0: $r=0.91, p<0.0001 ; \mathrm{FV} \mathrm{0.1:} r=0.65, p<0.02$

increase in fractional glycogen synthase activity (FV 0.1: $r=0.54, p<0.07$ and FV $0.0: r=0.06, \mathrm{NS}$ ) in the patients with Type 2 diabetes.

No correlation was found between muscle G6P concentration (mean of basal + insulin-stimulated) and plasma glucose concentration $(r=0.27$, NS) in the patients with Type 2 diabetes. An inverse correlation, however, was found between muscle G6P content and the insulinstimulated increase in FV $0.0(r=-0.67, p<0.02)$ in the Type 2 diabetic patients (Fig. 4). No significant correlation was found between muscle G6P content and insulinstimulated increase in FV 0.1 ( $r=-0.09$, NS).

Correlation analyses between plasma glucose concentrations, muscle free glucose concentrations, G6P concentrations and glycogen synthase activities in the normal subjects were all NS.

\section{Discussion}

The extent to which hyperglycaemia compensates for the various defects in intracellular glucose metabolism in Type 2 diabetic patients was the subject of recent publica- 

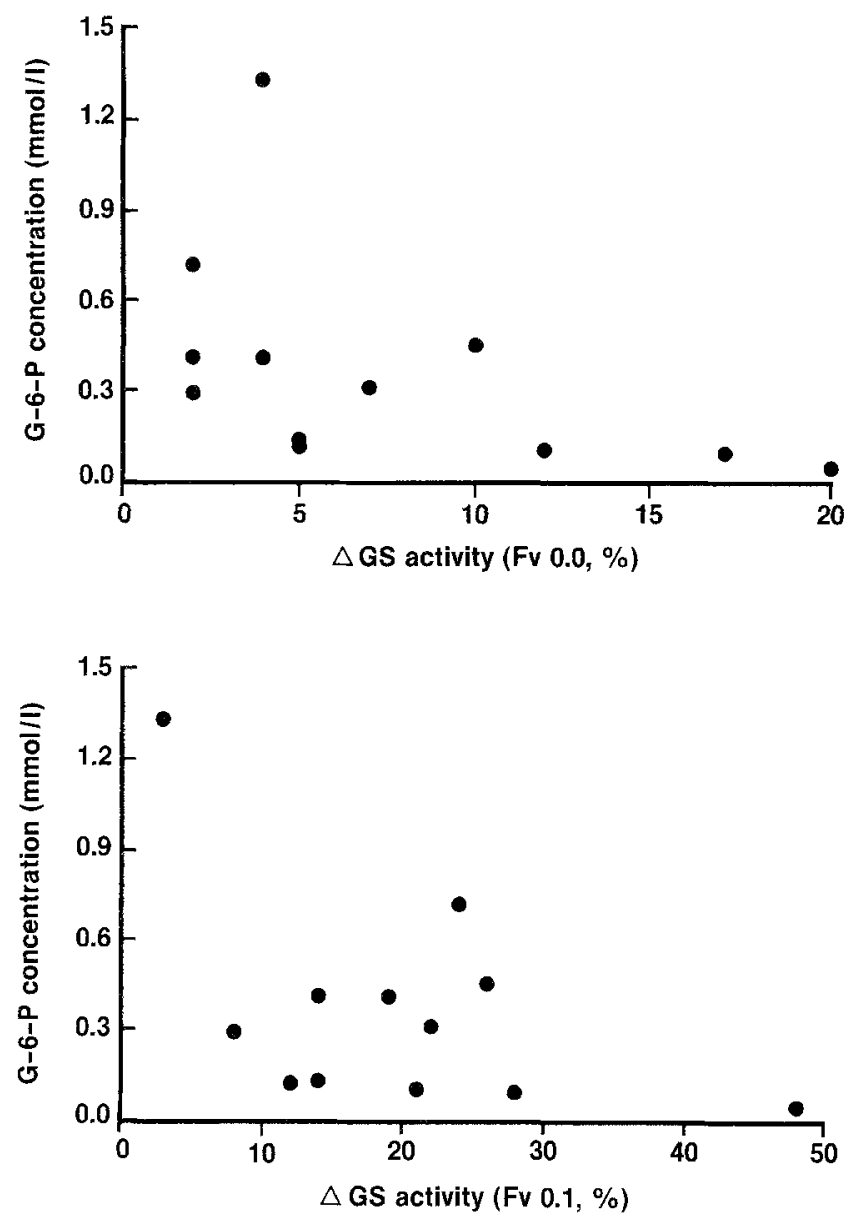

Fig.4. Relationship between increase in muscle glycogen synthase (GS) activity (fractional velocities (FV) at 0.0 and $0.1 \mathrm{mmol} / 1 \mathrm{glu}-$ cose 6-phosphate (G6P) during insulin infusion $\left(3 \mathrm{~h}, 40 \mathrm{mU} \cdot{ }^{-2}\right.$. min $^{-1}$ ) and G6P concentration in skeletal muscle in 12 patients with Type 2 (non-insulin dependent) diabetes mellitus. FV 0.0: $r=-0.67, p<0.02 ; \mathrm{FV} 0.1: r=-0.09, \mathrm{NS}$

tions from two different groups, in which contradictory results were reported. Thus, Thorburn et al. found that hyperglycaemia in Type 2 diabetes does not compensate for the defects in glucose oxidation and in muscle glycogen synthase activation $[35,36]$, whereas the defect in whole-body non-oxidative glucose metabolism was overcompensated during hyperglycaemia in their diabetic patients in the basal state and during insulin infusion. On the other hand, Kelley and Mandarino recently reported that the ambient level of fasting hyperglycaemia in Type 2 diabetic patients completely normalized the defects in both of the major pathways of intracellular glucose metabolism, including the activation of glycogen synthase in skeletal muscle $[8,37]$. Furthermore, using the limb balance technique, Kelley and Mandarino demonstrated an increased muscle glucose oxidation in the Type 2 diabetic patients during fasting hyperglycaemia [8].

Clearly, the finding in the present study of normal rates of basal and insulin-stimulated whole-body glucose oxidation and non-oxidative glucose metabolism during the ambient level of fasting hyperglycaemia in Type 2 diabetic patients supports the findings of Kelley and Mandarino $[8$, 37]. The explanation for the differences between this data and that from Thorburn et al. are not clear, however, but may be due to differences in selection of study subjects or in study design. Specifically, Thorburn et al had to increase the plasma glucose concentration markedly in the Type 2 diabetic patients above their ambient fasting blood glucose to about $20 \mathrm{mmol} / \mathrm{l}$ in order to match the glucose flux in these subjects to the flux in their normal control subjects. This indicates that the normal control subjects in the study of Thorburn et al. may have been extremely insulin sensitive, which may also explain the lack of normalization of muscle glycogen synthase activity in their diabetic patients during the matched glucose fluxes.

It should be noted that other previous studies have found either a normal $[6,16,38]$ or a decreased $[7,39,40]$ basal rate of whole-body glucose oxidation in fasting and hyperglycaemic Type 2 diabetic patients. These differences may be explained by differences between study subjects in BMI, or in different degrees of elevated fasting plasma insulin, glucose or NEFA concentrations. These are all factors known to influence the rate of whole-body glucose oxidation in human subjects. However, it may be important to emphasize that, in the basal postabsorptive state, only a small proportion of the rate of total wholebody glucose disposal and glucose oxidation is accounted for by skeletal muscle $(<20 \%)$ [41]. This means that the direct measurements by Kelley and Mandarino of muscle glucose oxidation, using the limb balance technique, cannot be directly compared with the measurements of whole-body glucose oxidation in the basal postprandial state. In addition, this implies that the different findings of basal rates of whole-body glucose oxidation in Type 2 diabetic patients may be due to the influence of the abovementioned factors on the rate of glucose oxidation in tissues other than skeletal muscle.

In contrast to the condition during low fasting insulin concentrations, skeletal muscle accounts for the majority of whole-body glucose disposal during high physiological insulin concentrations ( $>80 \%$ ) [41]. Therefore, the rates of whole-body glucose oxidation and non-oxidative glucose disposal during insulin infusion in the present study are likely to represent skeletal muscle glucose metabolism.

The normal muscle glycogen synthase activation during the isoglycaemic insulin infusion in the present study does not mean that the activation by insulin of muscle glycogen synthase is normal in patients with Type 2 diabetes. In contrast, these data demonstrate that higher plasma glucose and intracellular glucose concentrations, together with a higher muscle G6P content, are required to compensate for the previously demonstrated defective glycogen synthase insulin activation in these patients during euglycaemia $[4,8,13]$.

It was previously shown that hyperglycaemia per se does not stimulate the fractional activity of glycogen synthase in muscle biopsies from normal subjects during somatostatin infusion [42] or in Type 1 (insulin-dependent) diabetic subjects [43]. However, we demonstrate in the present study that hyperglycaemia normalizes the defective insulin activation of glycogen synthase in skeletal muscle in Type 2 diabetic patients during euglycaemia. This is in accordance with the data from Kelley and Man- 
darino for Type 2 diabetes $[8,37]$, and is also consistent with the finding that hyperglycaemia normalizes the defective insulin sensitivity of muscle glycogen synthase fractional activity in insulin resistant Type 1 diabetic patients [44]. Finally, the influence of glucose on glycogen synthase insulin activation is in accordance with data obtained in the isolated mouse soleus muscle demonstrating that, whereas glucose alone had no effect on muscle glycogen synthase activity, incubation with insulin plus glucose increased glycogen synthase activity more than incubation with insulin alone [45]. Thus, it appears that whereas glucose per se does not stimulate the fractional glycogen synthase activity in skeletal muscle, glucose has a permissive effect on the insulin activation of the enzyme.

Insulin sensitivity of muscle glycogen synthase is decreased in obese compared to lean normal subjects [4]. In the present study, the Type 2 diabetic patients were significantly more obese than the control subjects. Thus, hyperglycaemia in the present study normalized both the obesity-related and the diabetes-related defects in muscle glycogen synthase activation in the Type 2 diabetic patients.

The mechanism responsible for the compensatory effect of hyperglycaemia on fractional glycogen synthase activity may be through an enhancing effect of either the increased glucose or G6P concentration on the activity of glycogen synthase phosphatase. Glycogen synthase phosphatase is responsible for the dephosphorylation, and thus the activation, of glycogen synthase. The individual roles of glucose vs $\mathrm{G} 6 \mathrm{P}$ in compensating glycogen synthase activity may be complicated. Studies on the intact mouse diaphragm have indicated that especially G6P, and only to a small extent glucose per se, may stimulate the activity of glycogen synthase phosphatase [46]. The high correlation between intracellular free glucose concentrations and glycogen synthase insulin sensitivity in the present study suggests a primary role of glucose per se in increasing muscle glycogen synthase insulin sensitivity in patients with Type 2 diabetes. The inverse correlation between G6P concentrations and glycogen synthase insulin sensitivity, however, may suggest that low glycogen synthase activities causes an accumulation of G6P. On the other hand, an increasing G6P concentration may stimulate glycogen synthase allosterically $[47,48]$, which in turn may decrease the G6P concentration due to a higher turn-over rate of the substrate. Nevertheless, the muscle G6P concentration in vivo is determined not only by the rate of glycogen synthesis, but also by the rate of glucose uptake and phosphorylation (hexokinase), glycolysis and glycogenolysis. Therefore, we cannot exclude the increased G6P concentration in the Type 2 diabetic patients as being responsible for the compensated (normalized) fractional glycogen synthase activation.

The correlations between increments in fractional glycogen synthase activation and whole-body rates of nonoxidative glucose uptake confirm an important role of muscle glycogen synthase activity in determining in vivo insulin action. The present study suggests this to be the case not only during euglycaemia, but also during hyperglycaemia in patients with Type 2 diabetes.
The fractional glycogen synthase activity is supposed to merely reflect the covalent activation (degree of dephosphorylation) of the enzyme. However, it is unclear whether the increased muscle G6P concentration in the hyperglycaemic diabetic patients stimulates the rate of glycogen synthesis further through an additional in vivo allosteric activation of glycogen synthase, or alternatively, whether the increased muscle G6P content is reflected solely by the compensated (normalized) fractional glycogen synthase activity. The completely normalized insulin stimulated increase in muscle glycogen content and in in vivo non-oxidative glucose metabolism indicate that the increased muscle G6P content does not cause an additional increase in the rate of muscle glycogen synthesis in the diabetic patients. On the other hand, it is important to realize that measurements of insulin-stimulated non-oxidative glucose metabolism and increments in muscle glycogen content represent the net product of the rate of glycogen synthesis and the rate of glycogenolysis. There are some data to indicate that a major part of the G6P content in rat muscle biopsies, which have not been freezeclamped, represents G6P coming from glycogen due to glycogenolysis [49]. If this is the case in the present study, it may in fact suggest the presence of an increased rate of glycogenolysis in the diabetic patients, and it may furthermore provide an additional explanation for the inverse correlation betwen the muscle G6P content and glycogen synthase activity in these subjects. Therefore, we cannot exclude the theoretical possibility that the compensated glucose metabolism in the hyperglycaemic Type 2 diabetic patients includes an increased turnover rate of glycogen in skeletal muscle, i. e. an increased rate of glycogen synthesis together with an increased rate of glycogenolysis.

The higher free glucose and G6P concentrations in the Type 2 diabetic patients compared with the control subjects during similar glucose utilization rates and insulin concentrations suggests that glycogen synthase activity may be rate limiting for the insulin stimulated muscle glucose metabolism in patients with Type 2 diabetes. A defective glycogen synthase activity may cause an accumulation of muscle G6P and free glucose, in turn causing a decrease in glucose transport over the cell membrane due to the smaller glucose gradient. Thereafter, the increasing glucose and G6P concentrations outside and inside the cell may gradually improve glycogen synthase insulin sensitivity, and an increasing muscle G6P concentration may furthermore increase the allosteric activation of glycogen synthase. When the glucose concentration reaches a level where the glycogen synthase activity is sufficient to store glucose at a rate equal to the rate of glucose appearance, a newly compensated state may be achieved. Thus, the physiological implication of our data may be that hyperglycaemia in Type 2 diabetic patients may serve to compensate for insulin resistance and a defective endogenous insulin secretion [50] in order to maintain a normal intracellular glucose metabolism in skeletal muscles.

In conclusion, the present study demonstrates that both basal and insulin-stimulated rates of glucose oxidation and non-oxidative glucose disposal are fully compensated (normalized) in obese patients with Type 2 diabetes 
during fasting hyperglycaemia and isoglycaemic insulin infusion. Most importantly, we have demonstrated in patients with Type 2 diabetes that the muscle glycogen synthase activity is stimulated adequately when determined during a physiological isoglycaemic insulin infusion, and thus during a normalized glucose turnover rate. Furthermore, the patients with Type 2 diabetes had an increased intracellular concentration of free glucose and G6P during the physiological insulin infusion, suggesting that the rate limiting step in muscle glucose metabolism in patients with Type 2 diabetes is located after G6P. A high correlation between muscle free glucose concentration and insulin sensitivity of muscle glycogen synthase indicates an important compensatory role of glucose in the insulin activation of muscle glycogen synthase in patients with Type 2 diabetes.

Acknowledgements. The authors would like to acknowledge the expert technical assistance of Ms. A. Forman, Ms. K. Dyregaard, Ms. H. Vorup, Ms. B. Hansen, and Ms. B. Mottlau. Dr. E. A. Richter is acknowledged for providing laboratory facilities. The study was supported by grants from the Danish Medical Research Council, the Danish Diabetes Association, the Velux Foundation and from the Clinical Research Institute, Odense University Hospital.

\section{References}

1. DeFronzo R, Deibert D, Hendler R, Felig P, Soman V (1979) Insulin sensitivity and insulin binding to monocytes in maturityonset diabetes. J Clin Invest 63: 939-946

2. Kolterman O, Gray R, Griffin J et al. (1981) Receptor and postreceptor defects contribute to the insulin resistance in non-insulin dependent diabetes mellitus. J Clin Invest 68: 957-969

3. DeFronzo R, Gunnarson R, Björkman O, Olsson M, Wahren J (1985) Effect of insulin on peripheral and splanchnic glucose metabolism in non-insulin dependent (type 2) diabetes mellitus. J Clin Invest 76: 149-155

4. Damsbo P, Vaag A, Hother-Nielsen O, Beck-Nielsen H (1990) Reduced glycogen synthase activity in skeletal muscle from obese patients with and without Type 2 diabetes. Diabetologia 34: $239-245$

5. Meyer HU, Curchod B, Maeder P, Pahud E, Jequier E, Felber JP (1980) Modifications of glucose storage and oxidation in nonobese diabetics, measured by continuous indirect calorimetry. Diabetes 29: $752-756$

6. Boden G, Ray TK, Smith RH, Owen OE (1983) Carbohydrate oxidation and storage rates in obese non-insulin dependent diabetic patients. Effect of improving glycaemic control. Diabetes 32: 982-987

7. Golay A, DeFronzo RA, Ferrannini E et al. (1988) Oxidative and non-oxidative glucose metabolism in non-obese Type 2 (non-insulin-dependent) diabetic patients. Diabetologia 31:585591

8. Kelley DE, Mandarino LJ (1990) Hyperglycemia normalizes insulin-stimulated skeletal muscle glucose oxidation and storage in non-insulin-dependent diabetes mellitus. J Clin Invest 86: 1999_ 2007

9. Leloir LF, Olavaria JM, Goldenberg SH, Carminatti H (1959) Biosynthesis of glycogen from uridine diphosphate glucose. Arch Biochem Biophys 81: 508 520

10. Mandarino L, Wright K, Verity et al. (1987) Effects of insulin infusion on human skeletal muscle pyruvate dehydrogenase, phosphofructokinase, and glycogen synthase. J Clin Invest 80: 655663

11. Villar-Palasi C, Larner J (1960) Insulin-mediated effect on the activity of UDPG-glycogen transglucosylase of muscle. Biochim Biophys Acta 81: 508-520
12. Bogardus C, Lillioja S, Stone K, Mott D (1984) Correlation between muscle glycogen synthase activity and in vivo insulin action in man. J Clin Invest 73: 1185-1190

13. Johnson AB, Argyraki M, Thow JC, Brougthon D, Jones IR, Taylor R (1990) Effects of intensive dietary treatment on insulinstimulated skeletal muscle glycogen synthase activation and insulin secretion in newly presenting type 2 diabetic patients. Diab Med 7: 420-428

14. Revers RR, Fink R, Griffin J, Olefsky JM, Kolternman OG (1984) Influence of hyperglycemia on insulin's in vivo effects in type 11 diabetes. J Clin Invest 73: 664-672

15. McGuire EAH, Helderman JH, Tobin JD, Andres R, Berman M (1976) Effects of arterial versus venous sampling on analysis of glucose kinetics in man. J Appl Physio ${ }^{155: 628-634}$

16. Hother-Nielsen O, Beck-Nielsen H (1990) On the determination of basal glucose production rate in patients with Type 2 (non-insulin-dependent) diabetes using primed-continuous $3{ }^{3} \mathrm{H}$-glucose infusion. Diabetologia 33: 603-610

17. Frayn KN (1983) Calculation of substrate oxidation rates in vivo from gaseous exchange. J Appl Physiol 41: 565-573

18. Ferrannini $\mathrm{E}$ (1983) The theoretical basis of indirect calorimetry: a review. Metabolism 37: 287-301

19. Tappy L, Owen OE, Boden G (1988) Effect of hyperinsulinemia on urea pool size and substrate oxidation rates. Diabetes 37 : $1212-1216$

20. Steele R (1959) Influence of glucose loading and of injected insulin on hepatic glucose output. Ann NY Acad Sci 82: 420-430

21. Cowan JS, Hetenyi S (1971) Glucoregulatory responses in normal and diabetic dogs recorded by a new tracer method. Metabolism 20: $360-372$

22. Cobelli C, Mari A, Ferrannini E (1987) Non-steady state: error analysis of Steele's model and development for glucose kinetics. Am J Physiol 252: E679-E689

23. Lukaski HC, Johnson PE, Bolonchuk WW, Lykken GI (1985) Assessment of fat-free mass using bioelectrical impedance measurements of the human body. Am J Clin Nutr 41: 810-817

24. Lowry OH, Passoneau JV (1972) A flexible system of enzymatic analysis. Academic Press, New York

25. Sjøgaard G, Adams RP, Saltin B (1985) Water and ion shifts in skeletal muscle of humans with intense dynamic knee extension. Am J Physiol 248: R190-R196

26. Sjøgaard G, Saltin B (1982) Extra- and intracellular water spaces in muscles in man at rest and with dynamic exercise. Am J Physiol 243: R271-R280

27. Thomas J, Schlender K, Larner J (1968) A rapid filter paper assay for UDP-glucose-glycogen gluco-syltransferase, including an improved biosynthesis of UDP- ${ }^{14} \mathrm{C}$-glucose. Anal Biochem 25: 486-499

28. Lowry OH, Rosebrough NJ, Farr AL, Randall RJ (1951) Protein measurements with Folin phenol reagent. J Biol Chem 193: 265272

29. Andersen I, Hannibal S (1983) Analytical and economical optimization of a glucose method with immobilized enzymes. J Automatic Chem 5: 188-192

30. Heding LG (1972) Determination of total serum insulin (IRI) in insulin-treated diabetic patients. Diabetologia 8: 260-266

31. Heding LG (1975) Radioimmunological determination of human C-peptide in serum. Diabetologia 11:541-548

32. Itaya K, Michio U (1965) Colorimetric determination of free fatty acids in biological fluids. J Lipid Res $6: 16 \cdots 20$

33. Passonneau JV (1974) L-(+ )-lactate. Fluorometric method. In: Bergmeyer HV (ed) Methods of enzymatic analysis. Academic Press, New York, pp 1468-1472

34. Mortensen HB (1980) Quantitative determination of hemoglobin $\mathrm{A}_{1 \mathrm{c}}$ by thin layer isoelectric focusing. J Chromatogr 182 : 325-333

35. Thorburn AW, Gumbiner B, Bulcan F, Wallace P, Henry RR (1990) Intracellular glucose oxidation and glycogen synthase activity are reduced in non-insulin-dependent (Type II) diabetes independent of impaired glucose uptake. J Clin Invest 85: 522529 
36. Thorburn AW, Gumbiner B, Bulcan F, Brechtel G, Henry RR (1991) Multiple defects in muscle glycogen synthase activity contribute to reduced glycogen synthesis in non-insulin dependent diabetes mellitus. J Clin Invest 87: 489-495

37. Mandarino LJ, Consoli A, Kelley DE, Reilly JJ, Nurjhan N (1990) Fasting hyperglycemia normalizes oxidative and nonoxidative pathways of insulin-stimulated glucose metabolism in noninsulin-dependent diabetes mellitus. J Clin Endocrinol Metab 71: 1544-1551

38. Eriksson J, Franssila-Kallunki A, Ekstrand A et al. (1989) Early metabolic defects in persons at increased risk for non-insulin-dependent diabetes mellitus. N EngI J Med 321: 337-343

39. Ravussin E, Bogardus C, Schwartz RS et al. (1983) Thermic effect of infused glucose and insulin in man. Decreased response with increased insulin resistance in obesity and non-insulin-dependent diabetes mellitus. J Clin Invest 72: 893-902

40. Golay A, Felber JP, Jequier E, DeFronzo RA, Ferrannini E (1988) Metabolic basis of obesity and non-insulin-dependent diabetes mellitus. Diab Metab Rev 4: 727-747

41. DeFronzo RA, Jacot E, Jequier E, Maeder E, Wahren J, Felber JP (1981) Results from indirect calorimetry and hepatic and femoral venous catheterization. Diabetes 30: 1000-1007

42. Yki-Järvinen $\mathrm{H}$, Mott D, Young AA, Stone K, Bogardus C (1987) Regulation of glycogen synthase and phosphorylase activities by glucose and insulin in human skeletal muscle. J Clin Invest 80: 95-100

43. Vaag A, Damsbo P, Skött P, Richter EA (1990) Effect of hyperglycemia per se on glucose metabolism in skeletal muscles in patients with IDDM. Diabetes 39 [Suppl 1]: 14A (Abstract)

44. Yki-Järvinen H, Sahlin K, Ren JM, Koivisto VA (1990) Localization of rate-limiting defect for glucose disposal in skeletal muscle of insulin-resistant Type 1 diabetic patients. Diabetes 30: $157-167$

45. Le Marchand-Brustel Y, Freychet P (1981) Regulation of glycogen synthase activity in the isolated mouse soleus muscle. Ef- fect of insulin, epinephrine, glucose and antiinsulin receptor antibodies. Biochim Biophy Acta 677: 13-22

46. Oron Y, Larner J (1972) Insulin action in intact mouse diaphragm. I. Activation of glycogen sythase through stimulation of sugar transport and phosphorylation. Mol Cell Biochem 32: 153160

47. Rosell-Perez M, Villar-Palasci C, Larner J (1962) Studies on UDPG-glycogen transglycosylase. I.Preparation and differentiation of two activities of UDPG-glycogen transglucosylase from rat skeletal. Biochemistry 2: 669-675

48. Friedman DL, Larner J (1963) Studies on UDPG-beta-glucan transglucosylase. III. Interconversion of two forms of muscle UDPG-beta-glucan transglucosylase by a phosphorylation-dephosphorylation reaction sequence. Biochemistry 2: 669-675

49. Rossetti L, Giaccari A (1990) Relative contribution of glycogen synthesis and glycolysis to insulin-mediated glucose uptake. A dose-response euglycemic clamp study in normal and diabetic rats. J Clin Invest 85: 1785-1792

50. Ward WK, Bolgiano DC, McKnight B, Halter JB, Porte D Jr (1984) Diminished beta-cell secretory capacity in patients with non-insulin-dependent diabetes mellitus. J Clin Invest 74: 13181328

Received: 4 March 1991

and in final revised form: 23 September 1991

Dr. A. Vaag

Department of Endocrinology and Internal Medicine (M)

Odense University Hospital

Sdr. Boulevard

DK-5000 Odense C

Denmark 